\title{
Novel Radon Sub-Slab Suctioning System
}

Dpen Access

\author{
Torben Valdbjørn Rasmussen*
}

Danish Building Research Institute, Department of Construction and Health at Aalborg University - Cph, Copenhagen, Denmark

\begin{abstract}
A new principle for radon protection is currently presented which makes use of a system of horizontal pressurised air ducts located within the lower part of the rigid insulation layer of the ground-floor slab. The function of this system is based on the principles of pressure reduction within the zone below the ground-floor construction. For this purpose a new system of prefabricated lightweight elements is introduced. The effectiveness of the system is demonstrated for the case of a ground-floor reinforced concrete slab situated on top of a rigid insulation layer (consisting of a thermal insulation layer located on top of a capillary-breaking layer) mounted in turn on stable ground. The new system of prefabricated lightweight elements consists of the capillary-breaking layer and a pressure-reduction zone which is working as the radonsuction zone. The radon-suctioning layer is formed from a grid of horizontal air ducts with low pressure which are able to remove air and radon from the ground. Results showed the system to be effective in preventing radon infiltrating from the ground through the ground-floor slab, avoiding high concentrations of radon being accumulated inside houses. For the system to be effective, the pressure within the ducts must be lower than the pressure inside the house. The new principle was shown to be effective in preventing radon from polluting the indoor air by introducing low pressure in the horizontal grid of air ducts. A lower pressure than the pressure inside the building must be established. The prefabricated lightweight elements were integrated into the insulation layer below the material of the ground-floor slab. The element and the insulation material were made of expanded polystyrene. The new element can be handled by one man on site.
\end{abstract}

Keywords: Radon, protection, sub-slab, suctioning, system.

\section{INTRODUCTION}

Radon is a radioactive noble gas that develops as a result of the decay chains of uranium and thorium [1]. When radon decays into different radon daughters, it generates alpha, beta and gamma rays. These rays are harmful to human beings. Radon originates in the ground and is the primary source of natural radiation in most countries [2]. Therefore the geological character of the ground on which a building is situated sets the level for how high the radon concentration of the indoor air can become. Radon mainly infiltrates into a building by air infiltration from the ground through cracks or other unintended openings in the ground construction [3].

In 2009, the World Health Organization, WHO, recommended that requirements for the acceptable maximum radon concentration in indoor air should be tightened from 200 $\mathrm{Bq} / \mathrm{m}^{3}$ to $100 \mathrm{~Bq} / \mathrm{m}^{3}$. The new recommendations are a result of WHO's evaluation that radon is responsible for 3-14\% of lung-cancer incidents, depending on the average radon exposure in different countries [4]. These findings showed radon as the second-largest cause of lung cancer; smoking is still the principal cause. Radon exposure must be taken seriously in efforts to prevent radon-induced lung cancer due to the large number of people exposed daily in buildings, and especially in residential buildings [4], as a large number of residential buildings are built over a slab on the ground. An investigation shows that if people spend their whole life in a

\footnotetext{
*Address correspondence to this author at the Danish Building Research Institute, Department of Construction and Health at Aalborg University Cph, Copenhagen, Denmark; Tel: +45 9940 2272; Email: tvr@sbi.aau.dk
}

building with an average radon concentration in the indoor air exceeding $200 \mathrm{~Bq} / \mathrm{m}^{3}$, their risk of getting lung cancer is higher than $1 \%$ [5]. This is far too high, and higher than what, in other contexts, is an acceptable single-factor risk. Ensuring good quality of the indoor air includes focus on radon and methods for controlling radon concentration in the indoor air.

In 2010, the requirements recommended by WHO were implemented in the Danish Building Regulations. The Danish Building Regulations now stipulate a maximum radon concentration of $100 \mathrm{~Bq} / \mathrm{m}^{3}$ in the indoor air in all new buildings. For existing buildings, simple and cheap actions are recommended if the concentration ranges between 100 $\mathrm{Bq} / \mathrm{m}^{3}$ and $200 \mathrm{~Bq} / \mathrm{m}^{3}$ in the indoor air; however, if the radon concentration exceeds $200 \mathrm{~Bq} / \mathrm{m}^{3}$, immediate intervention is necessary and more comprehensive efforts and improvements are recommended in order to lower the concentration of radon in the indoor air [6]. The first radon provisions were introduced in the Danish Building Regulations in 1995 [7].

Solutions to prevent radon from polluting the indoor air are traditionally based on a combination of three different principles: 1) establishing a protective layer against radon by using airtight materials and membranes, 2) introducing pressure reduction in the zone underneath the ground-floor construction, and 3) providing effective dilution of the indoor air with outdoor air. Of these principles, 2) pressure reduction is considered by far the most efficient. Pressure reduction requires a permeable radon-suctioning layer. Shingles, pebbles or coated ceramic pellets are permeable materials traditionally used to create a capillary-breaking layer. However, to- 
day the capillary-breaking layer is made of rigid insulation material. Therefore, new solutions are needed that create a permeable layer within the lower capillary-breaking layer of the rigid insulation material in the ground-floor slab.

This paper presents a new prefabricated lightweight element designed to reduce and control pressure reduction of the zone underneath the ground-floor construction. The effect of the element has been demonstrated on a ground-floor slab, which was constructed as a concrete slab on top of a thermal-insulation layer above a capillary-breaking layer mounted on stable ground. The thermal insulation and the capillary-breaking layer consisted of a traditional rigid insulation material of expanded polystyrene, EPS. The new element integrates the capillary-breaking layer and the pressurereduction zone, denoted the radon-suctioning layer, in one element. The solution introduces a horizontal grid of air ducts pressurised to suck air and radon from the ground. Results showing the radon-suctioning layer and the principles for its establishment within the rigid insulation material are presented. Equations to predict the airflow within the ground-floor slab were developed. A finite difference program was used to calculate the airflow. Simulations of airflow within the rigid insulation material were shown for a number of pressure differences between the pressure indoors and the pressure in the air ducts. Simulations of the airflow within the rigid insulation material were carried out for both low-quality and high-quality EPS combined with flooring that is more and less airtight. Results were used to provide directions on how to obtain effective radon protection using a system containing a horizontal grid of air ducts pressurized within the rigid insulation material of a traditional groundfloor slab.

\section{MEASURES TO LIMIT RADON INDOORS}

Solutions to prevent radon from polluting the indoor air and to limit and control radon concentration in the indoor air are based on a combination of three different principles: establishing 1) a protective layer, 2) pressure reduction, and 3) ventilation. The three principles are shown in (Fig. 1).

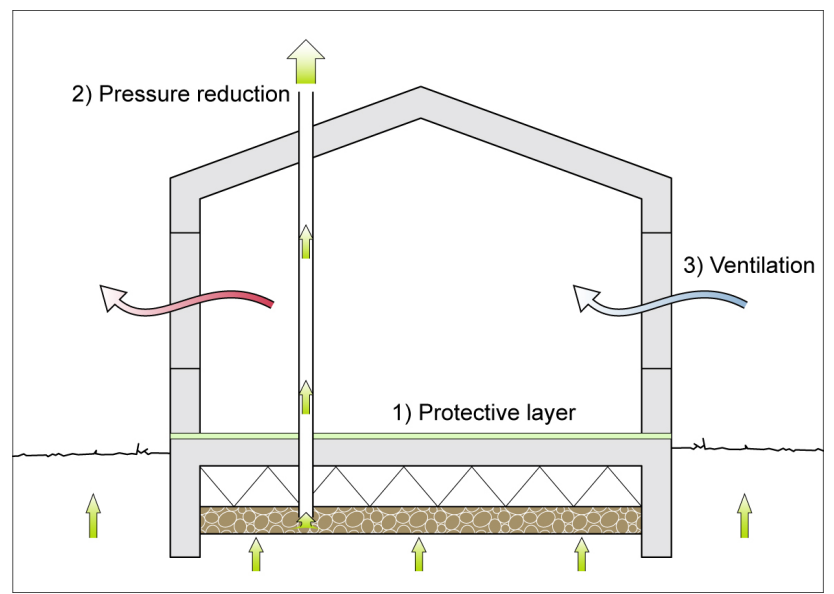

Fig. (1). By combining the three principles 1), 2) and 3), radon infiltration and concentration indoors can be controlled. 1) Establishing a protective layer against radon by using airtight materials and membranes, 2) introducing pressure reduction in the zone underneath the ground-floor construction, and 3) providing effective dilution of the indoor air with outdoor air, ventilation.

\section{PRESSURE LOWERING}

The most effective way of preventing air that may contain radon from infiltrating from the ground into a building is considered to be a radon-suctioning system [8]. The principle is that the pressure is lowered in the zone underneath the ground-floor slab of the building. The pressure difference can be up to $10 \mathrm{MPa}$ between the interior of the building and underlying ground-floor slab. This pressure difference can be equalized by establishing a connection between the atmosphere and a highly permeable layer underneath the building. In such a construction, the pressure difference across the floor construction of the building facing the ground will decrease and result in a decrease in the amount of ground air that can infiltrate. The radon-suctioning system can either be passive or active, i.e. creating suction through the stack effect only, or creating suction by means of a mechanical ventilator. A pipe can be led directly from the radon-suctioning layer and upwards to over the roof. Suction is introduced through the pipe to the radon-suctioning layer.

\section{THEORY}

The Heat2 [9], finite difference program, was used for the pressure equalization calculations. It was assumed that the pressure difference was so low that the air would not be compressed. Additionally, it was assumed that the speed of the air through the materials of the ground-floor slab was within the range of a laminar airflow. Furthermore, the individual materials were porous and homogeneous. Under these conditions, air flowing through a porous material can be described mathematically in the same way as a stationary thermal conductance problem. A stationary thermal conductance problem is described by:

$$
\frac{\partial}{\partial x}\left(k_{x} \frac{\partial T}{\partial x}\right)+\frac{\partial}{\partial y}\left(k_{y} \frac{\partial T}{\partial y}\right)+\frac{\partial}{\partial z}\left(k_{z} \frac{\partial T}{\partial z}\right)=0
$$

Where, $T$ is the temperature and $k_{x}, k_{y}, k_{z}$ are the thermal conductance in the $\mathrm{x}, \mathrm{y}, \mathrm{z}$ axes, respectively.

The differential equation, Equation (1) expresses that the total effect that is supplied to and removed from a control volume is equal to zero.

The result of a thermal conductance problem is a temperature distribution within the analysed element. From the temperature distribution, the effect that needs to be removed or absorbed through the borders to maintain the stationary temperature distribution can be determined. In the same way, the air pressure distribution can be calculated and the amount of air that needs to be removed or absorbed through the borders in order to maintain the stationary pressure distribution can be determined for porous materials. A stationary pressure distribution problem is described by:

$$
\frac{\partial}{\partial x}\left(q_{x} \frac{\partial P}{\partial x}\right)+\frac{\partial}{\partial y}\left(q_{y} \frac{\partial P}{\partial y}\right)+\frac{\partial}{\partial z}\left(q_{z} \frac{\partial P}{\partial z}\right)=0
$$

Where, $P$ is the pressure and $q_{x}, q_{y}, q_{z}$ are the pressure distribution in the $\mathrm{x}, \mathrm{y}, \mathrm{z}$ axes, respectively. 
Using the finite difference program, Heat2, for airpressure calculation, the temperature was replaced by the air pressure, the thermal conductance was replaced by the air permeability and the effect was replaced by the amount of air per time unit. A stationary air pressure problem described by Equation (2) then expresses that the amount of air that is brought in and the amount of air brought out of the control volume is equal to zero.

For the pressure analyses, the input data for the thermal conductance values were replaced by the air-permeability values and the prescribed temperatures were replaced by the prescribed air-pressure values. Calculations were performed to reach air-pressure equilibrium between the air pressure indoors and the air pressure in the ground. At the state of airpressure equilibrium, the amount of air per time unit necessary to remove from or add to the indoor environment through the upper surface of the concrete slab was determined.

Usually, the air permeability of a material is given as the resistance, or the Z-value, with the unit $\left(\mathrm{h} \mathrm{m}^{2} \mathrm{~Pa}\right) / \mathrm{g}$ describing a specific building component of a specific thickness. For these calculations, the air permeability must be determined as the reciprocal value of the Z-value multiplied by the thickness of the building component.

\section{RADON SUB-SLAB SUCTIONING SYSTEM}

The highly permeable and capillary-breaking layer underneath the building often consists of shingles, pebbles or coated ceramic pellets, for example, but can also be a layer of EPS with a horizontal grid of air ducts.

\subsection{Material}

The prefabricated element was made of EPS to form an element that could be used as the capillary-breaking layer and the radon-suctioning layer integrated in one element. The air permeability was $0.0144 \mathrm{~g} /(\mathrm{m} \mathrm{h} \mathrm{KPa})$ for an EPS with a density of $20 \mathrm{~kg} / \mathrm{m}^{3}$ and $0.0054 \mathrm{~g} /(\mathrm{m} \mathrm{h} \mathrm{KPa})$ for an EPS with a density of $32 \mathrm{~kg} / \mathrm{m}^{3}$, respectively.

\subsection{Design}

The prefabricated element was produced as units of 600 $\mathrm{mm}$ in length, $400 \mathrm{~mm}$ in width and $50 \mathrm{~mm}$ in thickness. A horizontal grid was cut out and removed from the upper surface of the element, thus creating air ducts $30 \mathrm{~mm}$ wide and $30 \mathrm{~mm}$ deep with a centre-centre distance of $100 \mathrm{~mm}$. At the edge of the element, an air duct $15 \mathrm{~mm}$ wide and $30 \mathrm{~mm}$ deep was cut out and removed. The element is shown in (Fig. 2).

\section{MODELLING}

Calculations of the airflow through the ground-floor slab were made. In addition the amount of air passing through the upper surface of the concrete slab was calculated, using a constant air pressure above the concrete slab representing the air pressure inside and a constant air pressure in the air ducts of the element combined with a constant air pressure in the ground underneath the ground-floor slab. The air pressure in the ground underneath the ground-floor slab was 101328.6 $\mathrm{Pa}$. The density of the ground was estimated at $1200 \mathrm{~g} / \mathrm{m}^{3}$ and the air pressure was calculated at a depth of $0.3 \mathrm{~m}$ using a force of gravity of $10 \mathrm{~m} / \mathrm{s}^{2}$. An adiabatic interface borders to the right and to the left of the model. The ground-floor slab is shown in Fig. (3) and the model used for the calculations is shown in (Fig. 4).

\section{RESULTS}

For the calculations, the air permeability of the concrete, the soil and the gravel was $0.018 \mathrm{~g} /(\mathrm{m} \mathrm{h} \mathrm{KPa}), 0.36 \mathrm{~g} /(\mathrm{m} \mathrm{h}$ $\mathrm{KPa})$ and $0.576 \mathrm{~g} /(\mathrm{m} \mathrm{h} \mathrm{KPa})$, respectively. The atmospheric pressure was $1 \mathrm{~atm}$, equal to $101325 \mathrm{~Pa}$. For the calculations, the pressure inside was $101321.25 \mathrm{~Pa}, 101323.24 \mathrm{~Pa}$ and $101324.85 \mathrm{~Pa}$, respectively [10], in combination with a number of different pressure levels in the air ducts of the radon sub-slab suctioning system of between $101325.00 \mathrm{~Pa}$ and $101320.00 \mathrm{~Pa}$. The thickness of the concrete and the layer of thermal insulation was $100 \mathrm{~mm}$ and $300 \mathrm{~mm}$, respectively. The thermal insulation was EPS with air
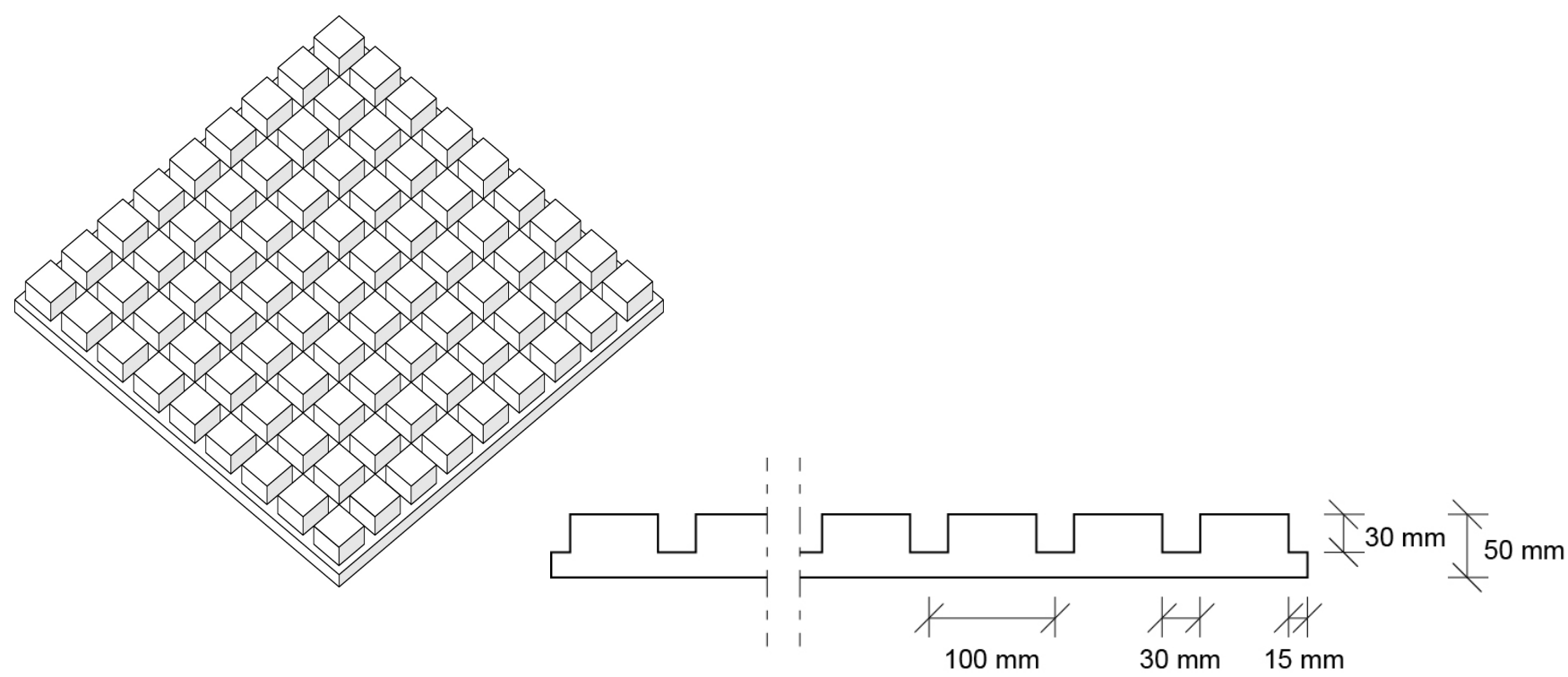

Fig. (2). The new prefabricated element made of EPS. Left; the element shown in perspective view. Right; a cross-section of the element. 

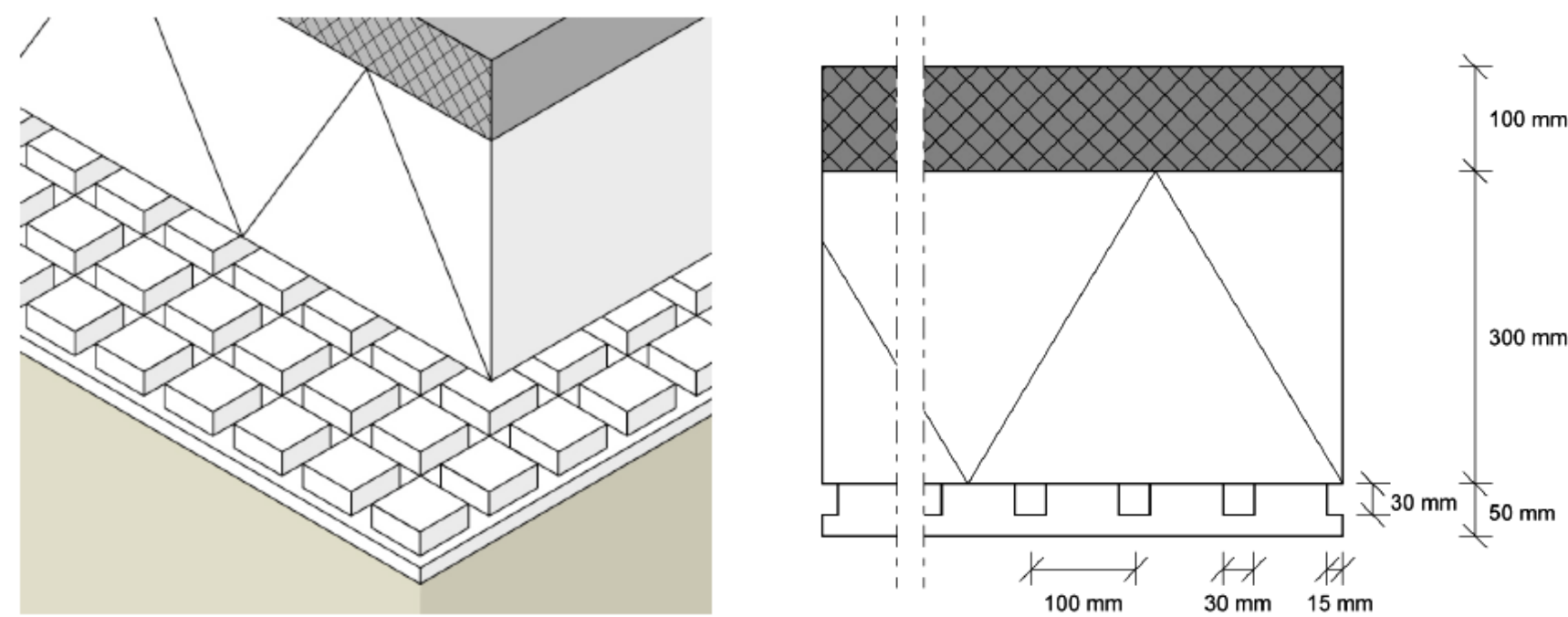

Fig. (3). The ground-floor slab was constructed of a reinforced concrete slab situated on top of a rigid insulation layer fitted above the new element mounted in turn on stable ground. The combined capillary-breaking layer and the radon-suctioning layer are shown as the new integrated element. Left; ground-floor slab shown in perspective view. Right; cross-section of the ground-floor slab.

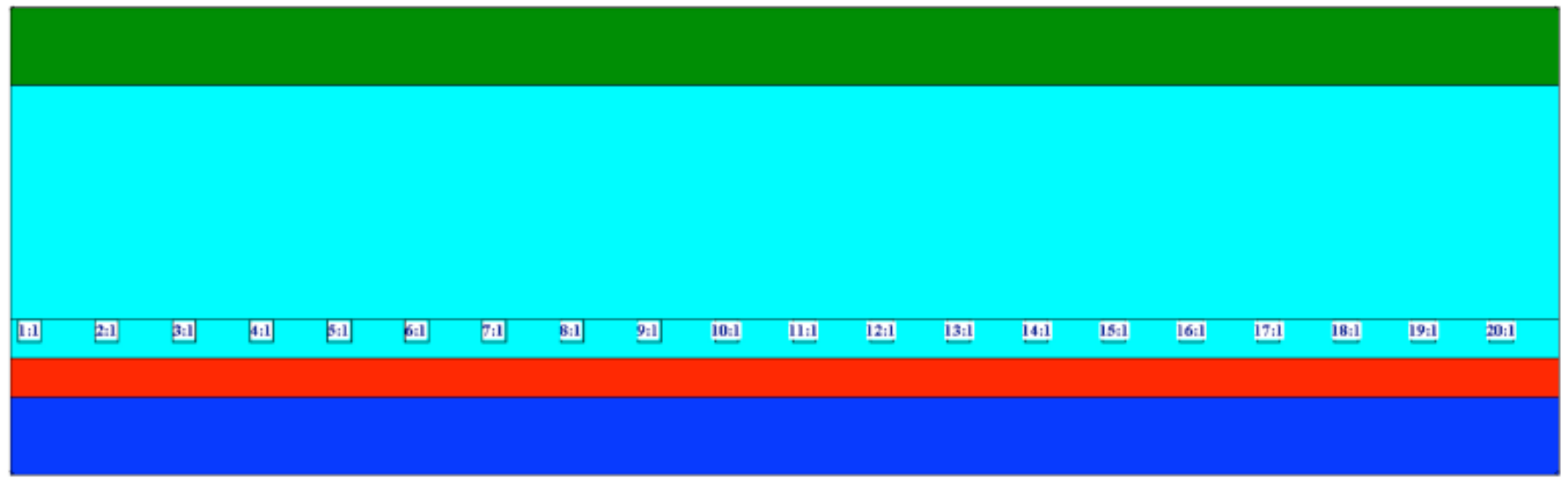

Fig. (4). The model used for calculations. The model includes a concrete slab on top of a thermal insulation layer above the new element mounted on stable ground. The horizontal grids of air ducts are shown as square units that are numbered 1:1 to 20:1. Usually the top-soil layer is removed from the area of the building. The excavated area is then covered with gravel to level the excavated area. Included in the model were $50 \mathrm{~mm}$ of gravel and $100 \mathrm{~mm}$ of soil. The model was $2.0 \mathrm{~m}$ in length.

permeability of $0.0144 \mathrm{~g} /(\mathrm{m} \mathrm{h} \mathrm{KPa})$. The radon sub-slab suctioning system was of EPS with an air permeability of $0.0144 \mathrm{~g} /(\mathrm{m} \mathrm{h} \mathrm{KPa})$. Results are shown in (Fig. 5).

The calculated air flow in the radon sub-slab suctioning system of EPS and the bordering thermal insulation layer of EPS around air ducts No. 13:1 and No. 14:1 is shown in Fig. (6) to Fig. (9). For the calculations, the air permeability of the concrete, the soil and the gravel was $0.018 \mathrm{~g} /(\mathrm{m} \mathrm{h} \mathrm{KPa})$, $0.36 \mathrm{~g} /(\mathrm{m} \mathrm{h} \mathrm{KPa})$ and $0.576 \mathrm{~g} /(\mathrm{m} \mathrm{h} \mathrm{KPa})$, respectively. The atmospheric pressure was $101325 \mathrm{~Pa}$. The pressure inside was $101323.24 \mathrm{~Pa}$ and the pressure in the air ducts of the radon sub-slab suctioning system was $101325.00 \mathrm{~Pa}, 101$ 323.24 Pa, $101322.00 \mathrm{~Pa}$ and $101320.00 \mathrm{~Pa}$ for Fig. (6), Fig. (7), Fig. (8) and Fig. (9) respectively. The thickness of the concrete and the layer of thermal insulation was $100 \mathrm{~mm}$ and $300 \mathrm{~mm}$, respectively. The thermal insulation was made of EPS with an air permeability of $0.0144 \mathrm{~g} /(\mathrm{m} \mathrm{h} \mathrm{KPa})$. The radon sub-slab suctioning system was made of EPS with an air permeability of $0.0144 \mathrm{~g} /(\mathrm{m} \mathrm{h} \mathrm{KPa})$. Arrows show the airflow and the length of the arrows visualizes the relative volume of air flowing.

Calculations were repeated assuming the concrete to be less air tight with an air permeability of $0.36 \mathrm{~g} /(\mathrm{m} \mathrm{h} \mathrm{KPa})$. In addition, the calculations were repeated for a more dense EPS with a density of $32 \mathrm{~kg} / \mathrm{m}^{3}$ and with an air permeability of $0.0054 \mathrm{~g} /(\mathrm{m} \mathrm{h} \mathrm{KPa})$. The air permeability was changed individually. For the calculations, the atmospheric pressure was $101325 \mathrm{~Pa}$. The pressure inside was $101323.24 \mathrm{~Pa}$ in combination with a number of different pressure levels in the air ducts of the radon sub-slab suctioning system, of between $101325.00 \mathrm{~Pa}$ and $101320.00 \mathrm{~Pa}$. The thickness of the concrete and the layer of thermal insulation was $100 \mathrm{~mm}$ and $300 \mathrm{~mm}$, respectively. Results are shown in (Fig. 10).

\section{DISCUSSION}

A new prefabricated lightweight element that can be used to reduce the air pressure in the zone underneath the groundfloor construction has been introduced. The new element is 


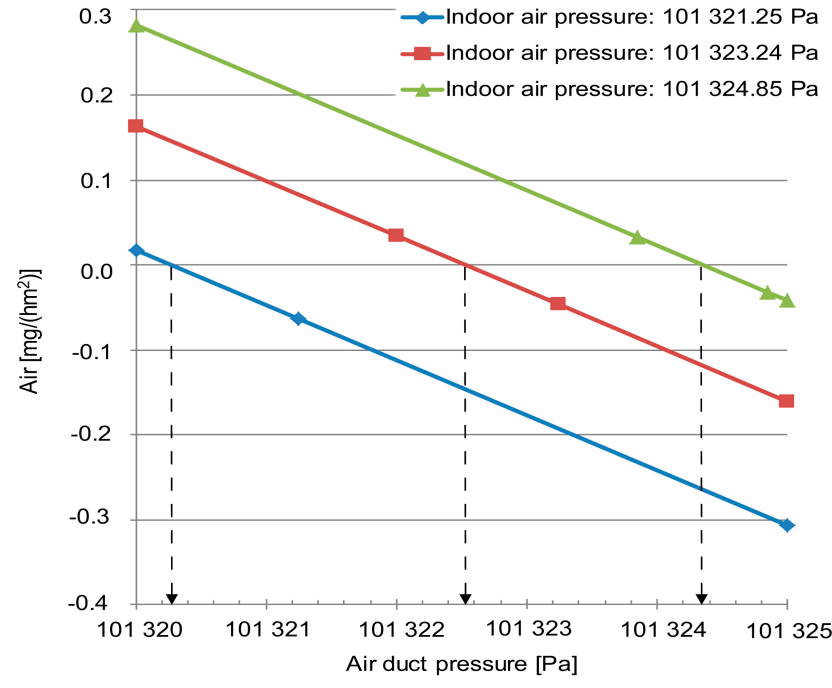

Fig. (5). Amount of air passing through the upper surface of the concrete slab in milligrams per hour per square metre. A positive number for the amount of air represents air moving through the ground-floor slab towards the air ducts.

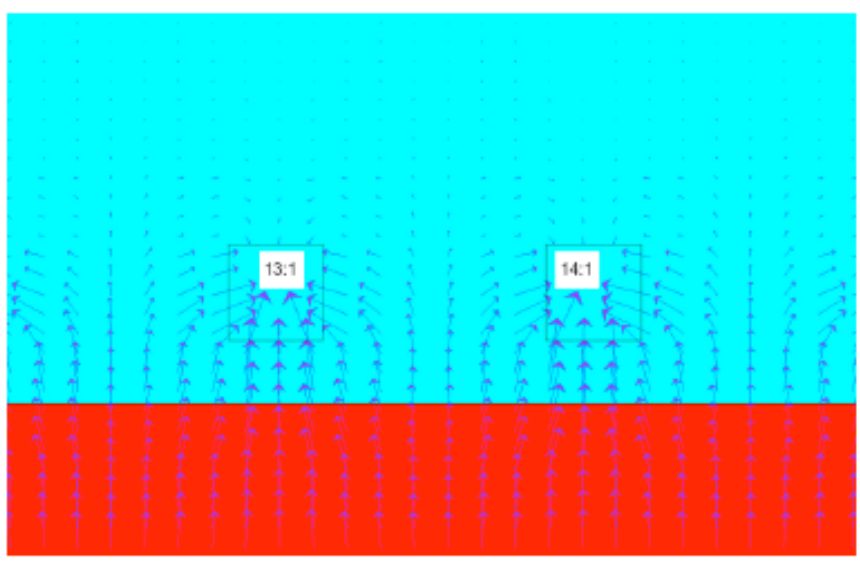

Fig. (7). The calculated airflow around air ducts No. 13:1 and No. 14:1 in the radon sub-slab suctioning system. For the calculation, the air permeability of the concrete was $0.018 \mathrm{~g} /(\mathrm{m} \mathrm{h} \mathrm{KPa})$. The pressure inside was $101323.24 \mathrm{~Pa}$ and the pressure in the air ducts was 101 $323.24 \mathrm{~Pa}$. The air permeability of EPS was $0.0144 \mathrm{~g} /(\mathrm{m} \mathrm{h} \mathrm{KPa})$. Arrows show the airflow and the length of the arrows visualizes the relative volume of air flowing.

made of expanded polystyrene, EPS. The element is produced as one integrated element consisting of units of 600 $\mathrm{mm}$ in length and $400 \mathrm{~mm}$ in width and $50 \mathrm{~mm}$ in thickness. A horizontal grid of air ducts is cut in the upper surface of the element, thus creating air ducts $30 \mathrm{~mm}$ wide and $30 \mathrm{~mm}$ deep with a centre-centre distance of $100 \mathrm{~mm}$. Along the edge of the upper surface of the element, air ducts $15 \mathrm{~mm}$ wide and $30 \mathrm{~mm}$ deep were cut and the EPS removed. The element is designed to be handled on site by one man.

Traditionally, a ground-floor slab is used that is constructed of a concrete slab on top of a thermal insulation layer above a capillary-breaking layer mounted on stable ground. The thermal insulation layer consists of a rigid insulation material. The capillary-breaking layer consists of ei-

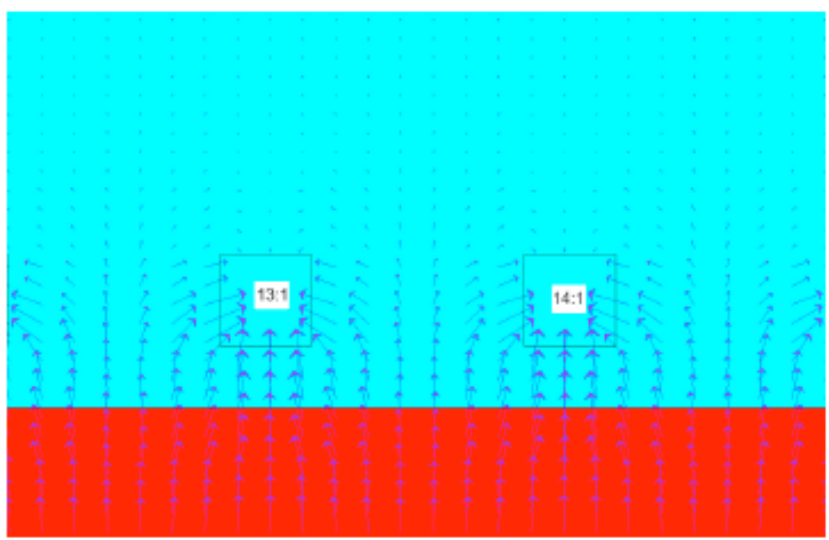

Fig. (6). The calculated airflow around air ducts No. 13:1 and No. 14:1 in the radon sub-slab suctioning system. For the calculation, the air permeability of the concrete was $0.018 \mathrm{~g} /(\mathrm{m} \mathrm{h} \mathrm{KPa})$. The pressure inside was $101323.24 \mathrm{~Pa}$ and the pressure in the air ducts was 101 $325.00 \mathrm{~Pa}$. The air permeability of EPS was $0.0144 \mathrm{~g} /(\mathrm{m} \mathrm{h} \mathrm{KPa})$. Arrows show the airflow and the length of the arrows visualizes the relative volume of air flowing.

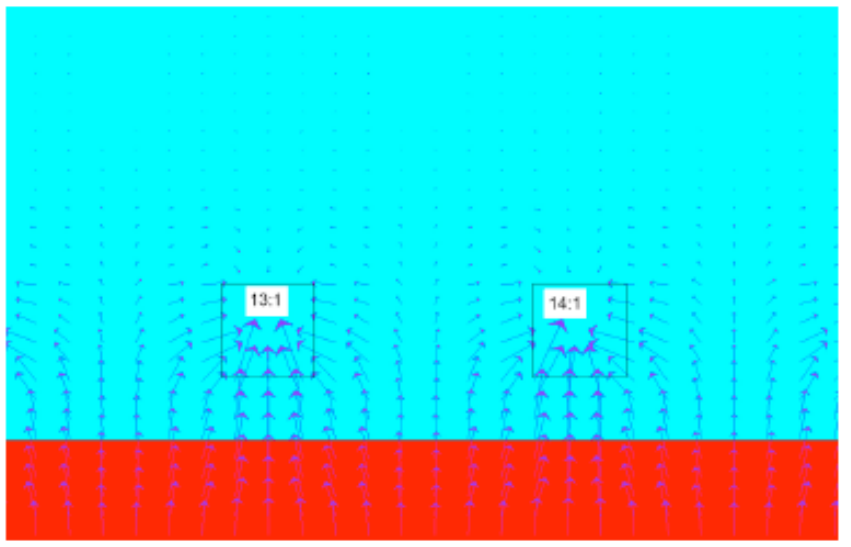

Fig. (8). The calculated airflow around air ducts No. 13:1 and No. 14:1 in the radon sub-slab suctioning system. For the calculation, the air permeability of the concrete was $0.018 \mathrm{~g} /(\mathrm{m} \mathrm{h} \mathrm{KPa})$. The pressure inside was $101323.24 \mathrm{~Pa}$ and the pressure in the air ducts was 101 $322.00 \mathrm{~Pa}$. The air permeability of EPS was $0.0144 \mathrm{~g} /(\mathrm{m} \mathrm{h} \mathrm{KPa})$. Arrows show the airflow and the length of the arrows visualizes the relative volume of air flowing.

ther a layer of a rigid insulation material on a thin layer of gravel to level the excavated area, or a layer of shingles, pebbles or coated ceramic pellets, for example. The new element makes it possible to combine the capillary-breaking layer and the radon-suctioning layer in one integrated element of EPS. The most effective way of preventing radon from infiltrating from the ground into the indoor air of a building is to lower the air pressure of the zone underneath the ground-floor construction. By lowering the air pressure of the zone underneath the ground-floor construction, the pressure difference across the floor construction can be lowered. Suction is introduced to the radon-suctioning layer. This suction can either be passive, by means of the stack effect created through a pipe led directly from the 


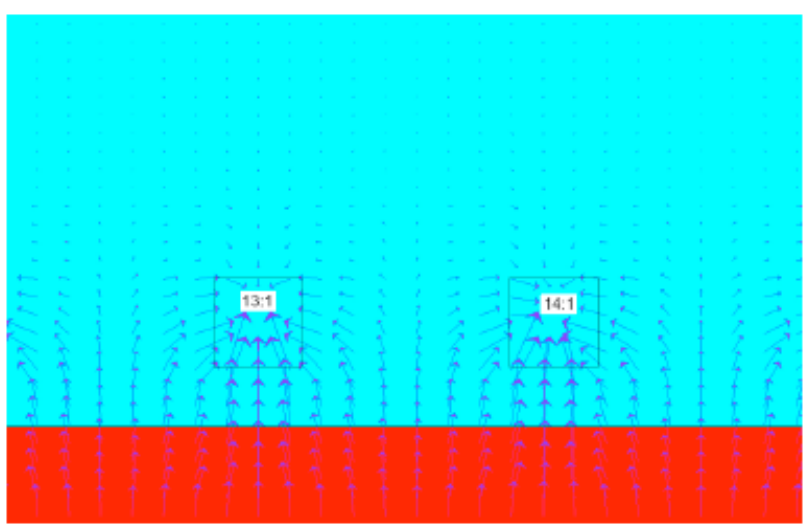

Fig. (9). The calculated airflow around air ducts No. 13:1 and No. $14: 1$ in the radon sub-slab suctioning system. For the calculation, the air permeability of the concrete was $0.018 \mathrm{~g} /(\mathrm{m} \mathrm{h} \mathrm{KPa})$. The pressure inside was $101323.24 \mathrm{~Pa}$ and the pressure in the air ducts was 101 $320.00 \mathrm{~Pa}$. The air permeability of EPS was $0.0144 \mathrm{~g} /(\mathrm{m} \mathrm{h} \mathrm{KPa})$. Arrows show the airflow and the length of the arrows visualizes the relative volume of air flowing.

radon-suctioning layer and upwards to over the roof, or active, by means of a mechanical ventilator added to the pipe. A horizontal grid serving as air ducts in a layer of EPS could be used as a permeable radon-suctioning layer underneath the floor construction of a building. The novel element can be used to lower the pressure difference across the floor construction of the building facing the ground, and in this way prevent ground air from infiltrating from the ground, and additionally prevent the risk of radon polluting the indoor air.

Calculations of the airflow through a ground-floor slab were made using a PC and a finite difference program. Mounted on stable ground, the ground-floor slab was constructed of a concrete slab on top of a thermal insulation layer and fitted above the new element that works as the combined capillary-breaking layer and the radon-suctioning layer. Calculations were performed with a constant indoor pressure and a constant pressure in the ground. Calculations of the airflow and movements of the air are shown in Fig. (6) to Fig. (9). Arrows show the direction of the airflow and the length of the arrows visualizes the relative volume of air flowing. The airflow and the direction of the moving air in the ground-floor construction are shown. The airflow in the area around individual air ducts in the radon sub-slab suctioning system is shown in detail for an air pressure difference of $1.76 \mathrm{~Pa}$ between the interior and the exterior of the building. The air pressure in the radon sub-slab suctioning system is $1.76 \mathrm{~Pa}$ higher than inside the building, Fig. (6), equal to the pressure inside the building, Fig. (7) and $1.24 \mathrm{~Pa}$ and $\mathrm{Pa} 3.24 \mathrm{~Pa}$ lower than inside the building, Fig. (8) and Fig. (9), respectively. Fig. (6) and Fig. (7) show that some air moves from the ground and escapes the radon sub-slab suc-

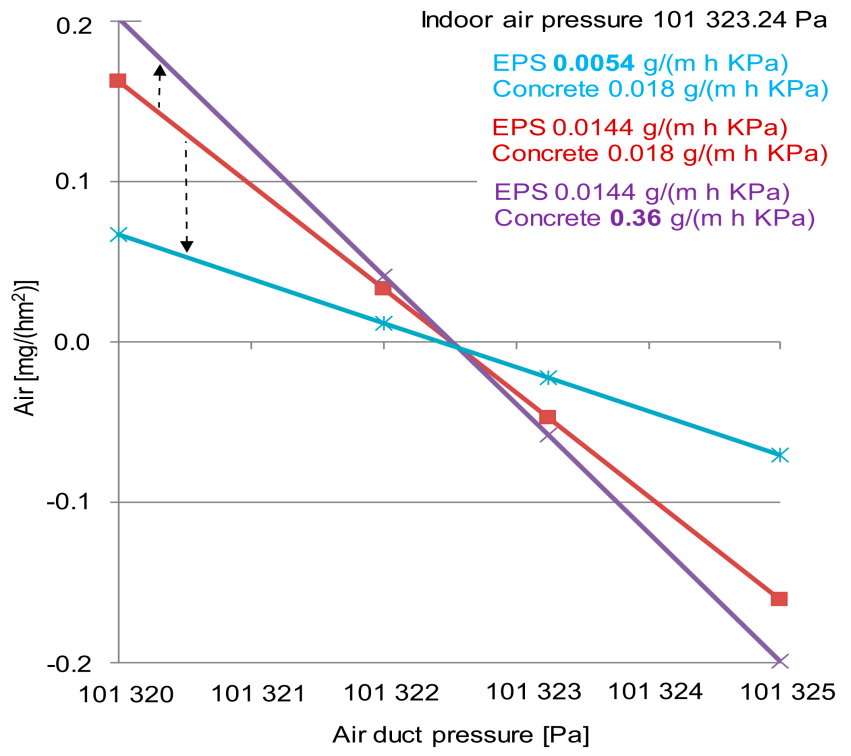

Fig. (10). Amount of air passing through the upper surface of the concrete slab in milligrams per hour per square metre. A positive number for the amount of air represents air moving through the ground-floor slab towards the air ducts. Additional calculations were made assuming less air-tight concrete with an air permeability of $0.36 \mathrm{~g} /(\mathrm{m} \mathrm{h} \mathrm{KPa})$ and assuming more dense EPS with a density of 32 $\mathrm{kg} / \mathrm{m}^{3}$ with air permeability of $0.0054 \mathrm{~g} /(\mathrm{m} \mathrm{h} \mathrm{KPa})$, respectively.

tioning system to infiltrate into the interior of the building. Fig. (8) and Fig. (9) show that air moves from the interior of the building to the radon sub-slab suctioning system.

Calculating the amount of air passing through the upper surface of the concrete slab shows that the air pressure in the air ducts of the radon-suctioning layer needs to be lower than the pressure inside in order to prevent radon and ground air from infiltrating from the ground through the floor construction. (Fig. 5) shows that the amount of air passing through the upper surface of the concrete slab is approximately zero for an indoor air pressure equal to $101321.25 \mathrm{~Pa}, 101323.24$ $\mathrm{Pa}$ and $101324.85 \mathrm{~Pa}$ and an air pressure in the air ducts equal to $101320.28 \mathrm{~Pa}, 101322.53 \mathrm{~Pa}$ and $101324.35 \mathrm{~Pa}$, respectively for an outdoor air pressure of $101325 \mathrm{~Pa}$. The pressure difference required over the ground-floor construction decreases as the air pressure inside approaches the outdoor air pressure.

Repeating calculations and changing individual parameters describing the use of a less airtight concrete slab and the use of EPS with a higher density are shown in (Fig. 10). Increasing the density of EPS results in a material with a more airtight structure. Changing the air permeability of the ground-floor construction is shown to have a minor effect and the amount of air passing through the upper surface of the concrete slab is approximately zero, see (Fig. 10). The zero condition is reached for an indoor air pressure equal to $101323.24 \mathrm{~Pa}$ and an air pressure in the air ducts equal to $101322.53 \mathrm{~Pa}$ for an outdoor air pressure of $101325 \mathrm{~Pa}$. However, as the ground-floor construction becomes more airtight, less air passes through the upper surface for a greater air pressure difference across the floor construction compared with the zero condition. 
The air pressure difference between the interior of a building and the radon sub-slab suctioning system can be controlled by controlling the air pressure in the horizontal grid of air ducts in the radon-suctioning layer. By controlling the air pressure in the horizontal grid of air ducts, infiltration of air and radon from the ground can be avoided. In this way the radon sub-slab suctioning system will suck up air and radon from the ground to be released to the atmosphere. One should be careful to release the ground air to the atmosphere at locations where it will not be drawn back into the building with outdoor air for ventilation.

If the pressure underneath the building is lower than the pressure inside it, air might be drawn through the concrete slab from the inside. This might be a concern if there is a risk of warm, humid air being drawn down through the floor construction, where it is cooled down in organic material and results in risk of mould growth. However, this is not a concern for the floor construction under consideration.

\section{CONCLUSIONS}

A new element made of expanded polystyrene, EPS, which can create a radon sub-slab suctioning system has been introduced. The element can be used to reduce the air pressure in the zone underneath the ground-floor construction and is integrated into the insulation layer. The element is produced as units that can be handled on site by one man. Elements are mounted on a levelled, stable basis of an excavated area of a building. The layer of elements introduces the radon-suctioning layer as a horizontal grid of air ducts. The principle is shown to be effective in preventing radon from polluting the indoor air by introducing low pressure in the horizontal grid of air ducts.

The principle has been demonstrated on a ground-floor slab, which was constructed as a reinforced concrete slab situated on top of a thermal-insulation layer mounted above the new element mounted on stable ground. The new element integrates the capillary-breaking layer and the radonsuctioning layer in one element. In this way, the new element is integrated into the insulation material of the ground-floor slab.

The principle has been demonstrated carrying out pressure equalisation calculations using a finite difference program. For the pressure equalisation calculations, it is assumed that the pressure difference is so low that the air will not be compressed. Additionally, it is assumed that the airflow through the materials of the ground-floor slab is in the range of a laminar airflow. Furthermore, it is assumed that the individual materials are porous and homogeneous. Results show that a pressure that is lower than the pressure inside the building must be introduced creating an efficient radon sub-slab suctioning system. The pressure difference required across the ground-floor construction decreases as the air pressure inside approaches the outdoor air pressure.
By lowering the air pressure of the zone underneath the ground-floor construction, the pressure difference across the floor construction can be increased. A pipe can be led directly from the radon-suctioning layer and upwards to above the roof. Suction is introduced to the radon-suctioning layer through the pipe. The suction can either be passive, taking avenge of the stack effect introduced in the pipe itself, or active, by means of a mechanical ventilator in the pipe. One should be careful not to release the ground air to the atmosphere in places where it will be drawn back into the building with outdoor air for ventilation.

Calculations have been carried out for an indoor air pressure equal to $101321.25 \mathrm{~Pa}, 101323.24 \mathrm{~Pa}$ and 101324.85 $\mathrm{Pa}$, an outdoor air pressure of $101325 \mathrm{~Pa}$ and an air pressure in the soil underneath the ground-floor slab of $101328.6 \mathrm{~Pa}$.

\section{CONFLICT OF INTEREST}

The authors confirm that this article content has no conflicts of interest.

\section{ACKNOWLEDGEMENTS}

This study was supported by the Danish Plastics Federation, EPS section.

\section{REFERENCES}

[1] B. Clavensjö, and G. Åkerblom, "Radonboken: Förebyggande åtgärder i nya byggnader”, (Bock for Radon, in Swedish), Formas: Stockholm, 2004, p. 106.

[2] Danish Enterprise and Construction Authority, "Radon and Dwellings", (Radon og enfamiliehuse, in Danish), Danish Enterprise and Construction Authority: Copenhagen, 2007, p. 15.

[3] R. Lehmann, H. Landfermann, A. Junkert, and U. Schöppler Eds., "Radon-Handbuch Deutschland." (The radon handbook, in German), Bundesministerium für Umwelt, Naturschutz und Reaktorsicherheit, Bonn, Bundesamt für Strahlenschutz: Salzgitter, (2001).

[4] H. Zeeb, and F. Shannoun, Eds., "WHO Handbook on indoor radon - a public health perspective", World Health Organization: Geneva, 2009, p. 94.

[5] C.E. Andersen, N.C. Bergsøe, J. Brendstrup, A. Damkjær, P. Gravesen, and K. Ulbak, "Radon 95: En undersøgelse af metoder til reduktion af radonkoncentrationen i danske enfamiliehuse", (Examination of measures to reduce the concentration of radon in Danish dwellings, in Danish), Riso National Laboratory: Roskilde, 1997, p. 108.

[6] Danish Enterprise and Construction Authority, "Danish Building Regulations 2010", (Bygningsreglement 2010, in Danish), Danish Enterprise and Construction Authority: Copenhagen, 2010, p. 253.

[7] Danish Enterprise and Construction Authority, "Danish Building Regulations 1995”, (Bygningsreglement 1995, in Danish), Danish Enterprise and Construction Authority: Copenhagen, 1995, p. 203.

[8] T.V. Rasmussen, "SBi-anvisning 233: Radonsikring af nye bygninger", (SBi-instructions 233: Measures preventing radon to penetrate into new buildings, in Danish), Danish Building Research Institute - Aalborg University: Hørsholm, 2010, p. 44.

[9] HEAT2, "HEAT2 - Heat transfer in two dimensions", BLOCON SWEDEN, Lund Group for Computational Building Physics, Department of Building Physics, Iliongränden 159, S-224 72 Lund, 2011, (Available: www.blocon.se, www.buildingphysics.com, http://www.buildingphysics.com/index-filer/heat2.htm).

[10] S. Bovbjerg, and L.B. Gunnarsen, "Radonkoncentrationen i nye enfamiliehuse." Danish Building Research Institute: Hørsholm, 2008, p. 28.

This is an open access article licensed under the terms of the Creative Commons Attribution Non-Commercial License (http://creativecommons.org/licenses/by-nc/3.0/) which permits unrestricted, non-commercial use, distribution and reproduction in any medium, provided the work is properly cited. 